\title{
Factor analysis of career success aspects that Malawians are happy with
}

\author{
Rhoda Cynthia Bakuwa ${ }^{1}$, Admore Kamanga ${ }^{2}$, Selina Mposa ${ }^{3}$, George Dzimbiri ${ }^{4}$ \\ 1,2,3,4 (Faculty of Commerce, The Polytechnic, University of Malawi, Malawi)
}

\begin{abstract}
This study was undertaken to examine the career success aspects that Malawians feel they have achieved a level they are happy with. Research on how individuals define a successful career is very important because it brings to light what aspects people in different cultures value most and would strive to attain as they progress through the various stages of their careers. However, just like in many non western contexts, little is known about how Malawians conceptualize career success. For this study, data were collected from 403 Malawians using a structured questionnaire which had 30 aspects of career success. Respondents were asked to reflect on each career success aspect and provide responses that focussed on how happy they were with the levels achieved with regard to each of the 30 career success aspects. A principal component factor analysis based on oblimin rotation results revealed that Malawians who took part in this study expressed happiness with the levels that they had achieved in as far as career success aspects related to learning and social relations were concerned than the levels achieved in as far as career success aspects related to entrepreneurship and financial achievement were concerned.
\end{abstract}

Keywords: Career, Career Success, Factor Analysis, Malawians

\section{Introduction}

The nature of career success is often bounded within and influenced by a country's unique context (Pringle \& Mallon, 2003). Shen et. al (2015) stress that culture studies show different work values across the globe, suggesting that conceptualizations of career success - being strongly influenced by individual and collective values - vary across cultures. Therefore, as observed by Poon et al (2015), although the study of career success has progressed significantly, the majority of career success research has been conducted in Western countries (predominantly in the USA) leading to calls for more research on this topic in more diverse career contexts (both within and across cultures). Just like in the case of Malaysia (Poon et al 2015) to date, little is known about how Malawians conceptualize careers. Research on how individuals define a successful career is very important because it brings to light what aspects people in different cultures value most and would strive to attain as they progress through the various stages of their careers. This study was therefore undertaken to examine the career success aspects that Malawians feel they have achieved a level they are happy with using factor analysis. In particular, the study adopted Principal Components Analysis (PCA) technique mainly because the underlying purpose for conducting factor analysis was to obtain an empirical summary of the data set. Tabachnick \& Fidell (2007:635) in their review of Principal Components Analysis (PCA) and Factor Analysis (FA) as factor analysis techniques conclude that... "if you are interested in a theoretical solution uncontaminated by unique and error variability....FA is your choice. If, on the other hand, you simply want an empirical summary of the data set, PCA is a better choice". PCA is usually the preferred method of factor extraction especially when the focus of an analysis searching for underlying structure is truly exploratory, as was the case in this study.

\section{An overview of career success}

A career is defined as a sequence of jobs an individual holds or work related experiences during one's work history (Arthur, Hall \& Lawrence 1989, Feldman 1996). The desired outcomes or accumulated achievements (real or perceived) that result from these work related experiences constitute career success (Judge, Higgins, Thoresen, \& Barrick, 1999). Similarly Arthur, Khapova, \& Wilderom (2005: 178), define career success as 'the accomplishment of desirable work - related outcomes at any point in a person's work experiences over time. According to (Supangco, 2011) while success in one's career is a natural expectation of individuals, the nature of that success depends on what one expects from it. Indeed individuals have different definitions of career success based on their assessment of their prospects (Ebadan \& Winstanley, 1997)

In the past, career success as represented in both academic research and popular literature, was viewed as something which can be objectively determined and measured solely through external criteria such as hierarchical position and salary level (Sturges, 1999). This is defined as objective measure of career success. However, Sturges 1999 observed that just as the career has an internal as well as an external dimension, so too career success consists of a subjective internal dimension, as well as the objective external perspective from 
which it is generally viewed. It has been suggested by Powell \& Mainiero (1993) that subjective internal success may in fact be a more important determinant of perceived career success for many people. Consequently, career success has been operationalized as objective and subjective measures (Supangco, 2011). Objective measures of career success pertain to those that can be observed and verified by others (Judge et. al (1995) while subjective measures of career success pertain to the individuals' own judgement of their career attainment. Such subjective perceptions of career success might be in form of personal feelings of career accomplishment (Hennequin, 2007). The positive psychological outcomes or achievements one has accumulated as a result of experiences over the span of working life define subjective measures of career success. Therefore definitions of career success are dynamic not static, reflecting development stages through which individuals pass, as well as a psychological adjustment to perceptions of the kind of success which is actually available to individuals (Sturges, 1999).

It is not surprising that more recent studies present a much broader picture of the major categories of career success. For example, Shen et al (2015) generate eleven major categories of career success in terms of personal values and preferences, task characteristics and relational orientations, hence expanding the existing dichotomy of objective success (salary and promotion) and subjective success (satisfaction). Similarly, Mayrhofer et al (2016), identify seven globally relevant meanings or dimensions of career success that people regularly consider when they evaluate their career: financial security, financial achievement, learning and development, work-life balance, positive relationships, positive impact, and entrepreneurship.

\section{Research questions}

1) How many reliable and interpretable components are there among the 30 career success aspects that were presented to respondents in this study?

2) If reliable components are identified, how might we interpret those components?

3) How much variance in the original set of 30 career success aspects is accounted for by the interpretable components identified in this study?

\section{Method}

Data were collected from 403 Malawians out of which $96.5 \%$ were employed full time and $3.5 \%$ were employed part time in four key occupations: Managers 31.5\%, Professionals 34.0\%, clerical and service workers $24.1 \%$, and skilled labour $10.4 \%$. In terms of gender $40.0 \%$ were females and $60.0 \%$ were males. Further $15.8 \%$ were in the age category 20-29 years, $49.2 \%$ were aged between 30 and 39 years, $24.6 \%$ were in the age category $40-49$ years, and $10.3 \%$ were aged 50 years and above.

A structured questionnaire with 30 aspects of career success was administered. The aspects were in two categories. Respondents were asked to reflect on each career aspect and firstly answer "how important they consider the aspect to how they view career success then secondly answer "whether they have achieved a level of the career aspect they were happy with". This report focuses on the second category of responses that focussed on how happy individuals were with the levels achieved with regard to the 30 career success aspects.

The 30 career aspects were subjected to Principal Components Analysis (PCA). Prior to performing PCA, the suitability of data for factor analysis was assessed. Tabachnick \& Fidell (2007:613) suggest that 'it is comforting to have at least 300 cases for factor analysis'. Therefore, with a sample size of 403 using pairwise deletion, the minimum amount of data for factor analysis was satisfied. Initially, the factorability of the 30 career aspects was examined. Several well recognised criteria for the factorability of a correlation were used. Firstly, it was observed that all the 30 career aspects correlated at least .3 with at least one other item suggesting reasonable factorability. Secondly, the Kaiser-Meyer-Olkin measure of sampling adequacy was .925 , above the commonly recommended value of .6 (Kaiser, 1974), and Bartlett's Test of Sphericity (Barlett 1954 as cited by Pallant 2010) was significant $(\chi 2(435)=4232.539, p=.000)$. Finally, the communalities were all above .3 further confirming that each career aspect shared some common variance with other aspects. Given these overall indicators, factor analysis was deemed suitable with all 30 career success aspects.

To determine how many components to extract - a widely used criterion was developed in 1960 by Kaiser, and become to be known as "Kaiser's rule". The rule states that only components whose eigenvalues are greater than 1 should be retained. An eigenvalue is defined as the amount of total variance explained by each component.

Factor analysis was then conducted using data reduction which utilized eigenvalue criteria and direct oblimin rotation. Six components emerged with eigenvalues of above 1. Examining these initial eigenvalues in the table of total variance, revealed that the first component had an eigenvalue of 10.058 and explained $33.53 \%$ of the variance. The second, third, fourth, fifth and sixth components each had eigenvalues of over 1 but less than 2 , and explained $6.61 \%, 5.81 \%, 4.25 \%, 3.97 \%, 3.88 \%$ of the variance respectively. In total the six components explained $58.05 \%$ of the variance. However, the eigenvalue criteria is only reliable when the number of variables is less than 30 and communalities are greater than .7. In this analysis although all the 
communalities were above .3 but all of them were less than .7 consequently the application of eigenvalue criteria was questionable in this case.

So to determine the number to extract, eigenvalue was not adequate since $\mathrm{N}>250$ but the mean communality was less than .60 therefore a scree plot was the most relevant criterion to determine extraction since $\mathrm{N}>250$ and communalities were $>.30$.

Assessment of the scree plot (Fig 1) indicated that eigenvalues after the first component dropped of drastically. There was quite a clear break between component one and two i.e. the plot changed its shape at component two. Component one captured much of the variance than the remaining components. Ideally, only component one, should have been retained. However, there was also a little break between the third and fourth components. Therefore because of the research context, components two and three were explored as well.

Consequently, for the final stage, a principal components factor analysis based on a three - component solution was done and the results are shown in Table 1. Only 3 communalities were less than .3 (Table 2). The three - component solution, which explained $45.95 \%$ of the variance unlike the earlier $58.05 \%$ for the six components, was preferred because of: (a) the 'leveling off' of eigenvalues on the scree plot after three factors; and (c) the insufficient number of primary loadings and difficulty of interpreting the fourth factor and subsequent components.

To aid the interpretation of the three components, oblimin rotation was performed. The rotated solution revealed a structure that could be interpreted. Except for one career aspect (having time for non-work interests) which did not load on any of the three components, all the other 29 career success aspects in this analysis had primary loadings over .3. Only four career success aspects (receiving incentives, perks or bonuses; having financial security; steadily making more money; and fulfilling a "mission" or "calling" through my career) had cross - loadings.

Inspection of the career success aspects with the highest loadings on each component as presented in Table 2 , led to the following interpretation based on the classification provided by Mayrhofer et al (2016): Component 1 based on the top eight career success aspects could be labelled learning, work-life balance and positive impact. Component 2 based on the top six career success aspects could be labelled entrepreneurship and financial achievement. Component 3 based on the top four career success aspects could be labelled positive relationships. Further, there were significant correlations of above .3 at .01 level between each of the composite scores of the three components which justified the use of an oblimin rotation: .356 between learning/work-life balance/positive impact and entrepreneurship/financial achievement; 424 between learning/work-life balance/positive impact and positive relationships; and .346 between entrepreneurship/financial achievement and positive relationships.

Table 3 shows the descriptive statistics of the career success aspects which had their primary loadings on each component. Higher scores indicated happiness with the level achieved in regard to the career success aspect. The results show that component 1 career success aspects and component 3 career success aspects have relatively higher mean scores than component 2 career success aspects. The mean scores for component 1 career success aspects ranged from 3.70 to 3.95 , for component 3 career success aspects, the scores ranged from 3.65 to 3.99 , whilst for component 2 career success aspects the mean scores ranged from 2.69 to 3.20. Overall, relatively large percentages of respondents strongly agreed/agreed that they had achieved the levels they were happy with for career success aspects under components 1 and 3.

\section{Conclusion}

Generally, the results of this factor analysis indicated that three components were underlying the responses of Malawians to the various aspects of career success and that these components were moderately internally consistent explaining $45.95 \%$ of the variance. Component 1 based on the top eight career success aspects was labelled learning, work-life balance and positive impact. Component 2 based on top six career success aspects was labelled entrepreneurship and financial achievement. Component 3 based on the top four career success aspects was labelled positive relationships. Overall, the original factor structure proposed by Mayrhofer et al (2016) was to a greater extent retained in this study. The results of this exploratory factor analysis, have revealed that Malawians who took part in this study expressed happiness with the levels that they had achieved in as far as career success aspects related to learning and social relations (work life balance, positive relationships and positive impact) were concerned. However, the Malawians expressed lower happiness with the levels achieved in as far as career success aspects related to entrepreneurship and financial achievement were concerned. As observed by Mayrhofer et al (2016), issues of learning and development are important in collectivist societies just like social relations. Malawi is a collectivist society. As such it is not just about an individual and the immediate family but it is also about the extended family relations and the entire community. It can therefore be concluded that the results of this study seem to suggest that Malawians are generally happy with the levels they have achieved in as far as these aspects that touch on the national culture are concerned. Of course, the above identified career success aspects have not yet been measured in terms of their impact and 
contribution to the individuals' overall conceptualization of a successful career. Hence, the need for further studies to be conducted so as to have a more comprehensive picture of career success in the context of Malawi.

\section{Acknowledgement}

This study was based on the insights from the broader on-going Cross Cultural Collaboration on Contemporary Careers $(5 \mathrm{C})$ project which is aimed at developing a more comprehensive view of how people understand their career, career success, and career transitions, informed by different kinds of data around the world. Special thanks to Professor Jon Briscoe, Co-founder of 5C Project.

\section{References}

[1]. Pringle, J.K. and Mallon, M. (2003), Challenges for the boundaryless odyssey. The International Journal of Human Resource Management, 14, 839 - 853. [1]

[2]. Shen, Y., Demel, B., Unite, J., Briscoe, J.P., Hall, D.T., Chudzikowski, K., Mayrhofer, W., Abdul - Ghani, R., Bogicevic Milikic, B., Colorado, O., Fei, Z., Las Heras, M., Ogliastri, E., Pazy, A., Poon, J.M.L., Shefer, D., Taniguchi, M. and Zikic, J. (2015). Career success across 11 countries: Implications for international human resource management, The International Journal of Human Resource Management, 26(13), 1753 - 1778, http://dx.doi.org/10.1080/09585192.2014.962562 [1]

[3]. Poon, J., Briscoe, J. Abdul - Ghani, R. and Jones, E. (2015). Meaning and determinants of career success: A Malaysian perspective, Journal of Work and Organizational Psychology, 31, 21-29. [1]

[4]. B. Tabachnick and L. Fidell, Using Multivariate statistics (Boston: Pearson Education, 2007) [1]

[5]. M. B. Arthur, D. T., Hall and B. S. Lawrence, Generating new directions in career theory: The case for a transdisciplinary approach in M. B. Arthur, D. T. Hall, \& B. S. Lawrence (Eds.), Handbook of career theory (Cambridge, MA: Cambridge University Press 1989) 7-25 [2]

[6]. Feldman, D. (1996). Managing careers in downsizing firms. Human Resource Management, 35(2), 145-161. [2]

[7]. Judge, T. A., Higgins, C. A., Thoresen, C. J., and Barrick, M. R. (1999). The Big Five personality traits, general mental ability, and career success across the life span, Personnel Psychology,52, 621-652. doi: 10.1111/j.1744-6570.1999.tb00174.x [2].

[8]. Arthur, M. B., Khapova, S.N., and Wilderom, C.P.M. (2005). Career success in a boundaryless career world, Journal of Organizational Behavior, 26, 177 -202. [2]

[9]. Supangco, V. T. (2011). Organizational and Individual determinants of career success. 4th Annual BSP-UP Professorial Chair Lectures, 21 - 23 February 2011, Bangko Sentral ng Pilipinas, Malate, Manila. [2]

[10]. Ebadan, G. \& D. Winstanley (1997). Downsizing, delayering and careers: The survivor's perspective. Human Resource Management Journal, 7(1), 79-91. [2]

[11]. Sturges, J. (1999). What it means to succeed: Personal conceptions of career success held by male and female managers at different ages, British Journal of Management, 10 239-252. doi: 10.1111/1467-8551.00130 [2]

[12]. G.N. Powell and L.A. Mainiero Getting ahead - in career and life - in Powell, G. (ed.), Women and Men in Management, $2^{\text {nd }}$ ed. (Sage, Newbury Park, 1993). [2]

[13]. Judge, T. A., Cable, D. M., Boudreau, J. W., and Bretz, R. D., Jr. (1995). An empirical investigation of the predictors of executive career success, Personnel Psychology, 48,485-519.doi: 10.1111/j.17446570.1995.tb01767.x [2]

[14]. Hennequin, E. (2007). What "career success" means to blue-collar workers, Career Development International, 12, 565-581. doi: $10.1108 / 13620430710822029$ [2]

[15]. Mayrhofer, W., Briscoe, J.P., Douglas T., Hall, T. Dickmann, M., Dries, N., Dysvik, A., Kaše, R., Parry,E., and Unite, J.(2016), Career success across the globe: Insights from the 5C project. Organizational Dynamics (2016), http://dx.doi.org/10.1016/ j.orgdyn.2016.07.005 - in press. [2]

[16]. Kaiser, H. (1974): An index of factorial simplicity, Psychometrika, 39, 31 - 6. [3]

[17]. J. Pallant, SPSS Survival Manual: A step by step guide to data analysis using SPSS (McGraw Hill, Berkshire, 2010) [3]

\section{Scree Plot}

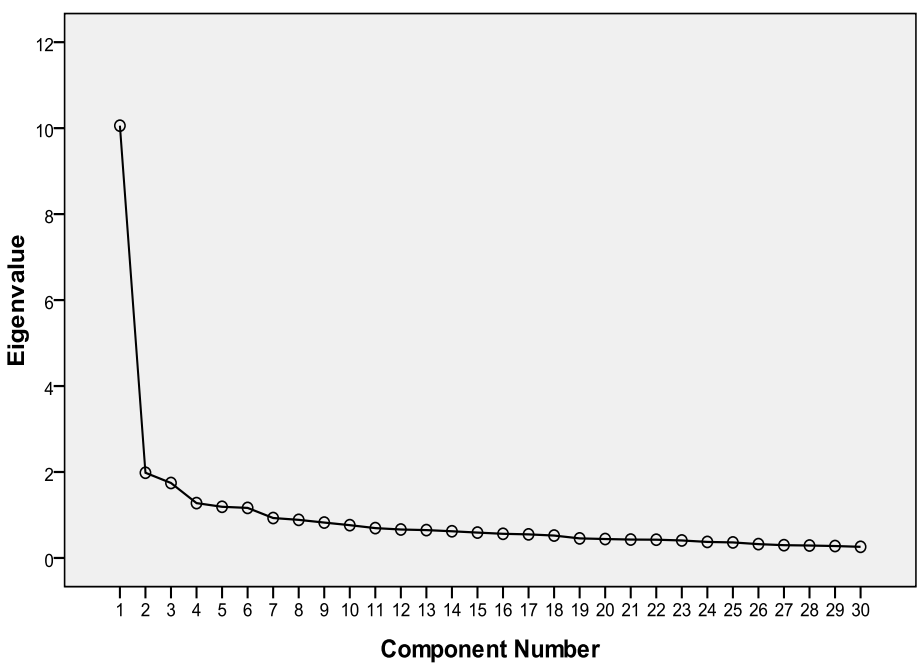

Figure 1: scree plot 
Table 1: Total Variance - Three Component Solution Total Variance Explained

\begin{tabular}{|c|c|c|c|c|c|c|c|}
\hline \multirow[b]{2}{*}{ Component } & \multicolumn{3}{|c|}{ Initial Eigenvalues } & \multicolumn{3}{|c|}{ Extraction Sums of Squared Loadings } & \multirow{2}{*}{$\begin{array}{c}\begin{array}{c}\text { Rotation } \\
\text { Sums of } \\
\text { Squared } \\
\text { Loadings }\end{array} \\
\text { Total }\end{array}$} \\
\hline & Total & $\%$ of Variance & Cumulative \% & Total & $\%$ of Variance & Cumulative \% & \\
\hline 1 & 10.058 & 33.525 & 33.525 & 10.058 & 33.525 & 33.525 & 8.429 \\
\hline 2 & 1.982 & 6.608 & 40.133 & 1.982 & 6.608 & 40.133 & 5.817 \\
\hline 3 & 1.744 & 5.814 & 45.948 & 1.744 & 5.814 & 45.948 & 5.686 \\
\hline 4 & 1.276 & 4.254 & 50.201 & & & & \\
\hline 5 & 1.190 & 3.968 & 54.170 & & & & \\
\hline 6 & 1.165 & 3.882 & 58.052 & & & & \\
\hline 7 & .929 & 3.097 & 61.149 & & & & \\
\hline 8 & .887 & 2.955 & 64.104 & & & & \\
\hline 9 & .823 & 2.745 & 66.849 & & & & \\
\hline 10 & .763 & 2.543 & 69.392 & & & & \\
\hline 11 & .694 & 2.315 & 71.707 & & & & \\
\hline 12 & .662 & 2.206 & 73.913 & & & & \\
\hline 13 & .648 & 2.160 & 76.073 & & & & \\
\hline 14 & .621 & 2.070 & 78.143 & & & & \\
\hline 15 & .590 & 1.968 & 80.111 & & & & \\
\hline 16 & .562 & 1.874 & 81.984 & & & & \\
\hline 17 & .549 & 1.829 & 83.813 & & & & \\
\hline 18 & .521 & 1.737 & 85.551 & & & & \\
\hline 19 & .455 & 1.517 & 87.068 & & & & \\
\hline 20 & .441 & 1.468 & 88.536 & & & & \\
\hline 21 & .428 & 1.427 & 89.963 & & & & \\
\hline 22 & .425 & 1.416 & 91.380 & & & & \\
\hline 23 & .407 & 1.357 & 92.736 & & & & \\
\hline 24 & .373 & 1.244 & 93.980 & & & & \\
\hline 25 & .361 & 1.204 & 95.184 & & & & \\
\hline 26 & .322 & 1.073 & 96.257 & & & & \\
\hline 27 & .297 & .991 & 97.247 & & & & \\
\hline 28 & .289 & .965 & 98.212 & & & & \\
\hline 29 & .277 & .925 & 99.137 & & & & \\
\hline 30 & .259 & .863 & 100.000 & & & & \\
\hline
\end{tabular}

Extraction Method: Principal Component Analysis.

a. When components are correlated, sums of squared loadings cannot be added to obtain a total variance.

Table 2: Factor Loadings and Communalities based on a PCA with Oblimin Rotation

\begin{tabular}{|c|c|c|c|c|}
\hline Career Aspect & $\begin{array}{l}\text { Component } \\
1\end{array}$ & $\begin{array}{l}\text { Component } \\
2\end{array}$ & $\begin{array}{l}\text { Component } \\
3\end{array}$ & Communality \\
\hline Getting positive feedback from supervisors & .716 & & & .494 \\
\hline Leaving people and places better as a result of my career & .693 & & & .479 \\
\hline Helping others & .687 & & & .429 \\
\hline Continuously learning throughout my career & .662 & & & .432 \\
\hline Expressing my true self throughout my career & .550 & & & .487 \\
\hline Experiencing challenges in my work & .474 & & & .268 \\
\hline Getting positive feedback from colleagues & .472 & & & .362 \\
\hline Becoming a better person as a result of my career & .468 & & & .444 \\
\hline Owning my own company & & .753 & & .543 \\
\hline Having the opportunity to be entrepreneurial & & .658 & & .592 \\
\hline Being self employed & & .633 & & .510 \\
\hline Achieving wealth & & .591 & & .472 \\
\hline Steadily making more money & .435 & .557 & & .603 \\
\hline Contributing to the development of others & & & .644 & .494 \\
\hline Experiencing positive relationships with peers and colleagues & & & .634 & .380 \\
\hline Achieving a balance between work and non work activities & & & .595 & .361 \\
\hline
\end{tabular}


Factor analysis of career success aspects that Malawians are happy with

\begin{tabular}{|l|l|l|l|l|}
\hline Experiencing positive relationships with superiors & & $\mathbf{. 5 7 2}$ & .410 \\
\hline Fulfilling a "mission" or "calling" through my career & & .320 & .560 & .523 \\
\hline Acquiring job-related skills through formal education and training & & & .518 & .397 \\
\hline Being able to provide for my family financially & & .313 & .498 & .532 \\
\hline Being able to provide the basic necessities & & & .439 & .283 \\
\hline Having time for non-work interests & & & .148 \\
\hline
\end{tabular}

Table 3: Descriptive Statistics of the Career Success Aspects under Each Component

\begin{tabular}{|c|c|c|c|c|c|c|c|}
\hline \multicolumn{2}{|c|}{ Career Aspect } & \multirow{2}{*}{$\begin{array}{l}\begin{array}{l}\text { Frequen } \\
\text { cy } \\
(\mathbf{N})\end{array} \\
379 \\
\end{array}$} & \multirow{2}{*}{$\begin{array}{l}\begin{array}{l}\text { Strongly } \\
\text { Agree/ Agree }\end{array} \\
75.0 \% \\
\end{array}$} & \multirow{2}{*}{$\begin{array}{l}\begin{array}{l}\text { Neither } \\
\text { Agree nor } \\
\text { Disagree }\end{array} \\
15.6 \% \\
\end{array}$} & \multirow{2}{*}{$\begin{array}{l}\text { Strongly } \\
\text { Disagree/Disag } \\
\text { ree } \\
9.5 \% \\
\end{array}$} & \multirow{2}{*}{$\begin{array}{l}\text { Mean } \\
3.92 \\
\end{array}$} & \multirow{2}{*}{$\begin{array}{l}\begin{array}{l}\text { Std. } \\
\text { Dev. }\end{array} \\
.943 \\
\end{array}$} \\
\hline Componen & Helping others & & & & & & \\
\hline \multirow[t]{7}{*}{$\mathbf{t} 1$} & $\begin{array}{l}\text { Learning continuously } \\
\text { throughout my career }\end{array}$ & 384 & $73.2 \%$ & $14.8 \%$ & $12.0 \%$ & 3.93 & 1.026 \\
\hline & $\begin{array}{l}\text { Doing work that gives one the } \\
\text { opportunity to learn. }\end{array}$ & 389 & $73.0 \%$ & $18.3 \%$ & $8.7 \%$ & 3.95 & .991 \\
\hline & $\begin{array}{l}\text { Having a career that has } \\
\text { meaning and purpose. }\end{array}$ & 384 & $70.0 \%$ & $19.3 \%$ & $10.7 \%$ & 3.90 & 1.016 \\
\hline & $\begin{array}{l}\text { Having the opportunity to be } \\
\text { innovative in one's work } \\
\text { activities }\end{array}$ & 382 & $64.7 \%$ & $19.9 \%$ & $15.4 \%$ & 3.71 & 1.072 \\
\hline & $\begin{array}{l}\text { Getting positive feedback } \\
\text { from supervisors }\end{array}$ & 377 & $63.7 \%$ & $23.3 \%$ & $13.0 \%$ & 3.72 & 1.036 \\
\hline & $\begin{array}{l}\text { Achieving a satisfying balance } \\
\text { between work and family life }\end{array}$ & 386 & $62.4 \%$ & $25.1 \%$ & $12.4 \%$ & 3.74 & 1.069 \\
\hline & $\begin{array}{l}\text { Leaving people and places } \\
\text { better as a result of my career }\end{array}$ & 379 & $61.2 \%$ & $24.5 \%$ & $14.3 \%$ & 3.70 & 1.090 \\
\hline \multirow[t]{6}{*}{$\begin{array}{l}\text { Componen } \\
\text { t } 2\end{array}$} & $\begin{array}{l}\text { Having the opportunity to be } \\
\text { entrepreneurial }\end{array}$ & 381 & $42.7 \%$ & $24.7 \%$ & $32.6 \%$ & 3.20 & 1.289 \\
\hline & Steadily making more money & 385 & $40.2 \%$ & $27.5 \%$ & $32.2 \%$ & 3.12 & 1.244 \\
\hline & Running my own company & 373 & $37.8 \%$ & $20.4 \%$ & $41.8 \%$ & 2.95 & 1.382 \\
\hline & Being self employed & 382 & $34.3 \%$ & $23.0 \%$ & $42.7 \%$ & 2.89 & 1.311 \\
\hline & Achieving wealth & 379 & $30.8 \%$ & $24.5 \%$ & $44.5 \%$ & 2.86 & 1.192 \\
\hline & Owning my own company & 372 & $29.8 \%$ & $18.8 \%$ & $51.3 \%$ & 2.69 & 1.348 \\
\hline \multirow[t]{4}{*}{$\begin{array}{l}\text { Componen } \\
\text { t } 3\end{array}$} & $\begin{array}{l}\text { Experiencing positive } \\
\text { relationships with peers and } \\
\text { colleagues }\end{array}$ & 366 & $77.8 \%$ & $16.4 \%$ & $5.8 \%$ & 3.99 & .893 \\
\hline & $\begin{array}{l}\text { Experiencing positive } \\
\text { relationships with superiors }\end{array}$ & 373 & $74.5 \%$ & $18.5 \%$ & $7.0 \%$ & 3.95 & .915 \\
\hline & $\begin{array}{l}\text { Contributing to the } \\
\text { development of others }\end{array}$ & 378 & $70.9 \%$ & $18.8 \%$ & $10.4 \%$ & 3.91 & 1.005 \\
\hline & $\begin{array}{l}\text { Achieving a balance between } \\
\text { work and non work activities }\end{array}$ & 373 & $63.8 \%$ & $20.9 \%$ & $15.3 \%$ & 3.65 & 1.059 \\
\hline
\end{tabular}

